\title{
NC-PROgRAMMing FOR ROLLING ROTATIONALLY ASYMMETRICAL WORKPIECES
}

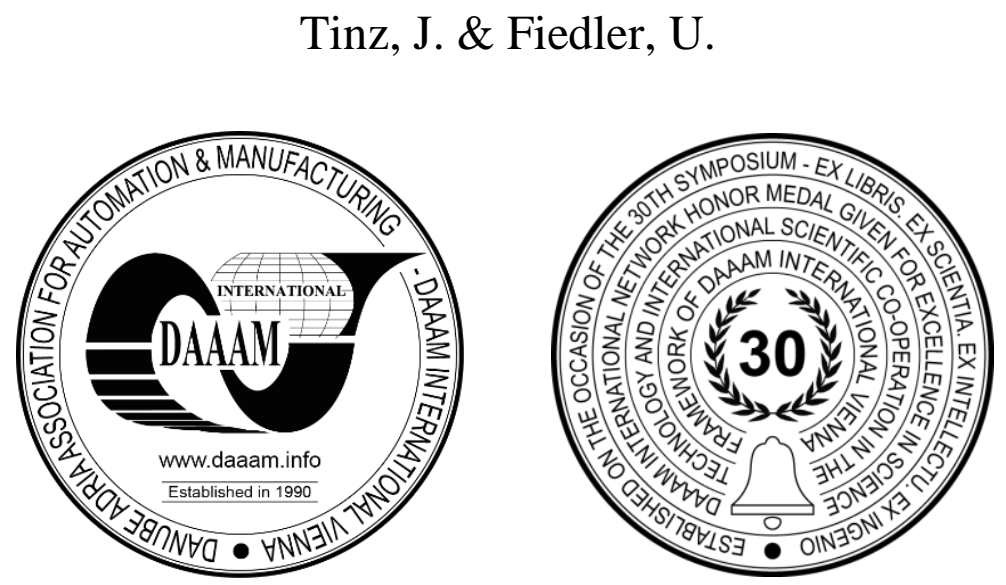

This Publication has to be referred as: Tinz, J[an] \& Fiedler, U[do] (2020). NC-Programming for Rolling Rotationally Asymmetrical Workpieces, Proceedings of the 31st DAAAM International Symposium, pp.0765-0770, B. Katalinic (Ed.), Published by DAAAM International, ISBN 978-3-902734-29-7, ISSN 1726-9679, Vienna, Austria DOI: $10.2507 / 31$ st.daaam.proceedings.106

\begin{abstract}
An innovative process route for weight-reduced and wear-resistant components is being developed by rolling and turning sintered metal in the research project „OST“ funded by the hessian government. For this purpose, the raw parts in the form of sintered pump cams are rolled in a lathe with a diamond-coated ball in order to densify the edge zone of the sintered metal. Due to the rotationally asymmetrical geometry of the cam, the rotation of the main spindle must be synchronized with the radial infeed of the machine axes in order to avoid a collision of the rolling tool with the workpiece within one spindle revolution. The NC program for controlling the CNC turning and milling centre is calculated in a spreadsheet calculation program by defining the lateral surface of the cam via Cartesian coordinate points. A transformation of the Cartesian coordinates into polar coordinates calculates the necessary dependence between the radius of the cam for the infeed of the rolling tool and the polar angle for the orientation of the main spindle. The tool paths are then generated by linear interpolation of the calculated points on the cam surface and the defined feed along the Z-axis.
\end{abstract}

Keywords: numerical control; programming; rolling; turning

\section{Introduction}

The trend in the automotive industry towards ever more complex components requires constantly increasing demands on their durability and functionality. Thus, the "OST" project is aiming to combine the manufacturing processes of sintering and rolling into an innovative process route in order to develop an economical production for wear-resistant functional components with rotationally asymmetric geometry. This new process route could optimise the production of camshafts, which are still used in large quantities in valve-controlled internal combustion engines and in a wide variety of pump systems such as water pumps, power steering pumps and heat pumps.

Up to now, camshafts have been manufactured by casting, forging or assembling individually manufactured cams, while cast camshafts can only endure a low Hertzian pressure without subsequent treatment [1]. For the production of assembled camshafts, powder metallurgy can be used to produce workpieces with complex geometry at low cost. The mechanical properties can be improved by densifying the edge zone of the workpiece [2], for example by rolling the sintered metal. A reduction in production time is also achieved by reducing the number of processing steps, so that combined turning and rolling tools lead to an increase in productivity and surface quality [3]. 
In addition, rolling generates macroscopic residual compressive stresses in the component [4], which increase the durability of the strained functional surfaces [5] and can be measured by x-ray diffraction [6]. Finally, the processing of rotationally asymmetrical components made of sintered metal in a CNC lathe machine requires the synchronisation of the spindle rotation with the radial infeed of the turning or rolling tool to follow the given geometry and to avoid collision between the workpiece and the tool. Thus, the aim of this work is to determine the tool paths that allow the rolling of rotationally asymmetrical workpieces. For this purpose, the tool paths are calculated from the defined geometry of the workpiece in a spreadsheet program according to the DIN 66025 standard and transferred to an NC program for controlling the turning machine. This procedure allows this manufacturing strategy to be used on any CNC machine, independent of manufacturer and control system.

\section{Tool paths for manufacturing an eccentric trunnion}

\subsection{Generation of a three-axis turning operation}

The calculation of the tool paths for turning and rolling rotationally asymmetrical components requires a mathematical description of the surface in order to define the translatory movement of the tool along the $\mathrm{X}$ and $\mathrm{Z}$ axes as a function of the rotational $\mathrm{C}$-axis of the main spindle. An eccentric trunnion as shown in figure 1a represents a simple geometric shape, which can be defined by the radius of the eccentric trunnion $\mathrm{R}$ and the offset $\mathrm{D}$ between the centre of the eccentricity and the centre of rotation. The three-dimensional kinematics of the turning process is therefore reduced to the two-dimensional $\mathrm{XY}$ plane of the workpiece coordinate system, where the Y-axis of the tool remains fixed at the height of the rotation point $P_{R}$.

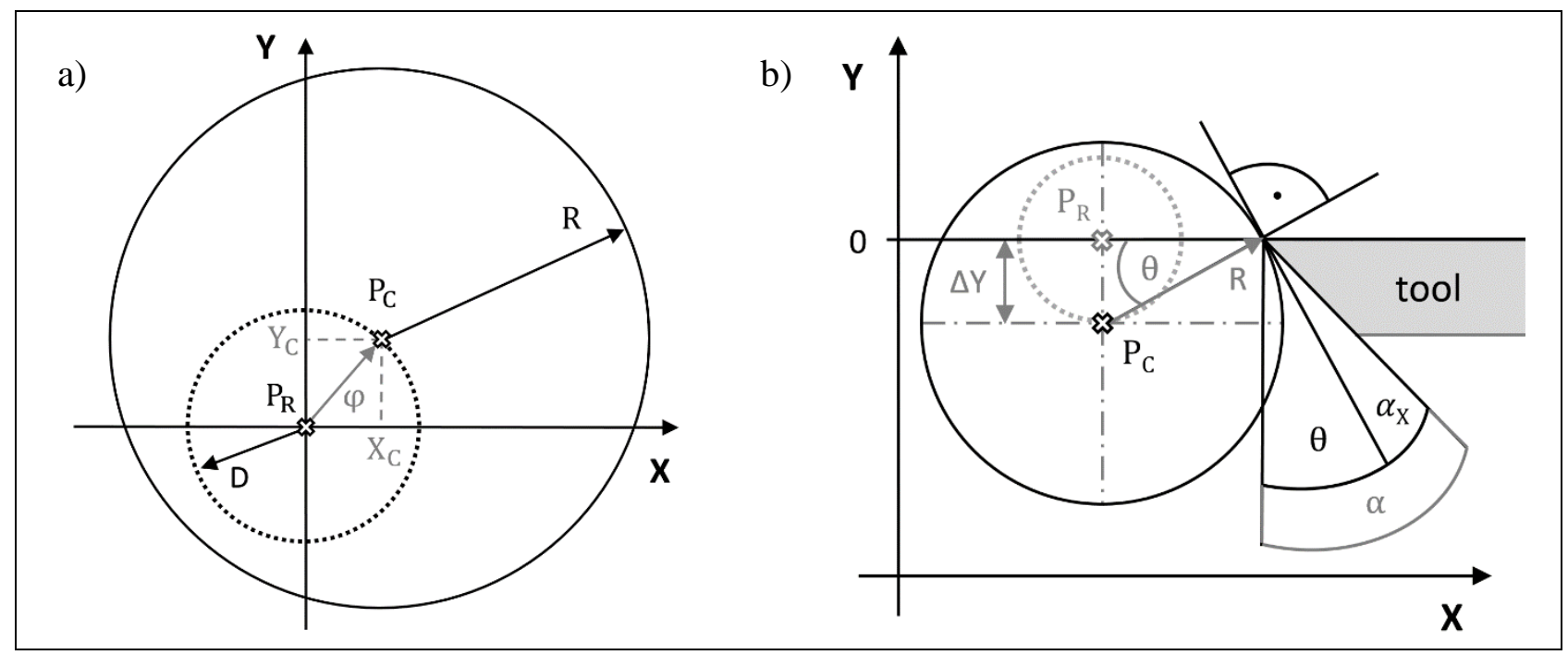

Fig. 1a. Definition of the eccentric trunnion; Fig. 1b. Limiting the clearance angle.

The centre point $\mathrm{P}_{\mathrm{C}}$ of the eccentric trunnion can be defined by Cartesian coordinates, so that the distance to the centre of rotation $P_{R}$ forms a right-angled triangle with $X_{C}$ and $Y_{C}$ as sides. From this follows the definition of equation (1) for the calculation of the hypotenuse $\mathrm{D}$.

$$
\mathrm{D}=\sqrt{\left(\mathrm{X}_{\mathrm{C}}\right)^{2}+\left(\mathrm{Y}_{\mathrm{C}}\right)^{2}}
$$

During the turning process, the rotation of the workpiece via the polar angle $\varphi$ creates a circle with the radius $\mathrm{D}$, on which the centre $\mathrm{P}_{\mathrm{C}}$ of the eccentricity is located. This allows the infeed of the turning tool along the $\mathrm{X}$-axis to be calculated according to equation (2) using the offset from the centre of rotation $\mathrm{D}$ and the radius of the eccentric trunnion $\mathrm{R}$.

$$
\mathrm{X}=\cos \varphi \cdot \mathrm{D}+\mathrm{R}
$$

As shown in figure $1 \mathrm{~b}$, this three-axis turning process leads to a limitation of the clearance angle on the turning tool, as the tool is not moved perpendicular to the cutting plane of the workpiece during the turning process. With the rotation of the workpiece, a further offset $\Delta \mathrm{Y}$ occurs between the centre $\mathrm{P}_{\mathrm{C}}$ of the eccentric trunnion and the tool tip, forming together with the radius $\mathrm{R}$ of the eccentric trunnion a correction angle $\theta$ according to equation (3).

$$
\sin \theta=\Delta \mathrm{Y} / \mathrm{R}
$$


Following equation (4), the correction angle $\theta$ reduces the clearance angle $\alpha$ of the turning tool to the maximum clearance angle $\alpha_{\mathrm{x}}[7]$.

$$
\alpha_{\mathrm{x}}=\alpha-\theta
$$

The calculation of the tool position along the Z-axis is based on the feed per full rotation $\mathrm{f}$ of the main spindle. For this purpose, as shown in equation (5), all integer multiples of the spindle rotation $\mathrm{N}$ are determined using the polar angle $\varphi$.

$$
\mathrm{Z}=\mathrm{N} \cdot \frac{\varphi}{360^{\circ}} \cdot \mathrm{f}
$$

From equation (3) it follows that a three-axis turning operation is limited by a small radius on the eccentric trunnion and a large offset from the centre of rotation over the finite clearance angle of the turning tool. This limitation of the clearance angle can be avoided by extending the kinematics to a simultaneous four-axis turning operation.

\subsection{Generation of a four-axis turning operation}

If the rotatory movement of the $\mathrm{C}$-axis and the translatory movements of the $\mathrm{X}$ and $\mathrm{Z}$ axes are extended by a movement of the Y-axis, the tool can also be moved orthogonally to the surface of an asymmetrical workpiece while the main spindle is rotating. In the example of an eccentric trunnion in Figure 1b, equation (6) can be used to compensate the offset $\Delta \mathrm{Y}$ between the centre $\mathrm{P}_{\mathrm{C}}$ of the eccentric trunnion and the tool tip by moving the $\mathrm{Y}$-axis.

$$
\mathrm{Y}=\sin \varphi \cdot \mathrm{D}
$$

In this case, the tool is always positioned perpendicular to the cutting plane, so that no correction angle is formed and the clearance angle of the tool is not limited. However, the execution of an NC program in real time, which is based on the calculated tool paths of this simultaneous four-axis operation, requires a high acceleration of the $\mathrm{X}$ and $\mathrm{Y}$ axes [8]. In order to reduce the vibration of the machine tool and the necessary acceleration, the exact stop points of the tool can be replaced by a tolerable rounding of corner points in the NC program. Depending on the programmed increment of the polar angle, a corresponding number of blocks per spindle revolution must be read and processed by the machine control system. In addition to high acceleration, this also requires fast data processing. Here, the block cycle time determines the data transfer rate in the CNC control system [9], which limits the spindle speed during the turning process. For the production of rotationally symmetrical components, it is recommended to reduce the number of coordinate points to be calculated based on the NC program.

\section{Tool paths for manufacturing rotationally asymmetrical cams}

\subsection{Generation of a three-axis turning operation}

The calculation of the translatory axes $\mathrm{X}$ and $\mathrm{Z}$ and the movement of the rotatory $\mathrm{C}$-axis for turning and rolling rotationally asymmetrical cams is based on an extension of the eccentric trunnion. Thus, Figure 2 shows how the lateral surface of a pump cam is composed of four connected quarter circles in the XY plane of the workpiece coordinate system. Here the centre of each quarter circle rotates during the turning operation as before on a circle with a radius of $D$, which corresponds to the offset of the circle centres from the centre of rotation. In order to avoid a limitation of the spindle speed due to the high effort for the CNC control system, the outer surface of the cam is defined by a linear interpolation from only 16 coordinate points. With a stroke of up to $8 \mathrm{~mm}$, a hydrostatically mounted ball in the rolling tool compensates the difference between the generated tool paths and the nominal geometry of the workpiece during the rolling process. In order to calculate the tool paths, a lateral surface transformation of the Cartesian coordinate points via a calculation of the polar coordinates is required. The polar coordinates on the lateral surface define the infeed of the X-axis via the function $\mathrm{R}_{\mathrm{C}}$ depending on the polar angle $\varphi$ according to equation (7).

$$
\mathrm{X}=\mathrm{R}_{\mathrm{C}}(\varphi)
$$

Because of the mirror-symmetrical arrangement of the quarter circles, the calculation of the rolling tool on the $\mathrm{X}$-axis can be represented at all 16 coordinate points via points $\mathrm{P}_{1}, \mathrm{P}_{2}$ and $\mathrm{P}_{3}$. To illustrate this, equation (8) shows the calculation of the cam radius $R_{C}$ via the defined Cartesian coordinates $X_{3}$ and $Y_{3}$ using the example of coordinate point $P_{3}$.

$$
\mathrm{R}_{\mathrm{C}}=\mathrm{R}_{3}=\sqrt{\mathrm{X}_{3}^{2}+\mathrm{Y}_{3}^{2}}
$$




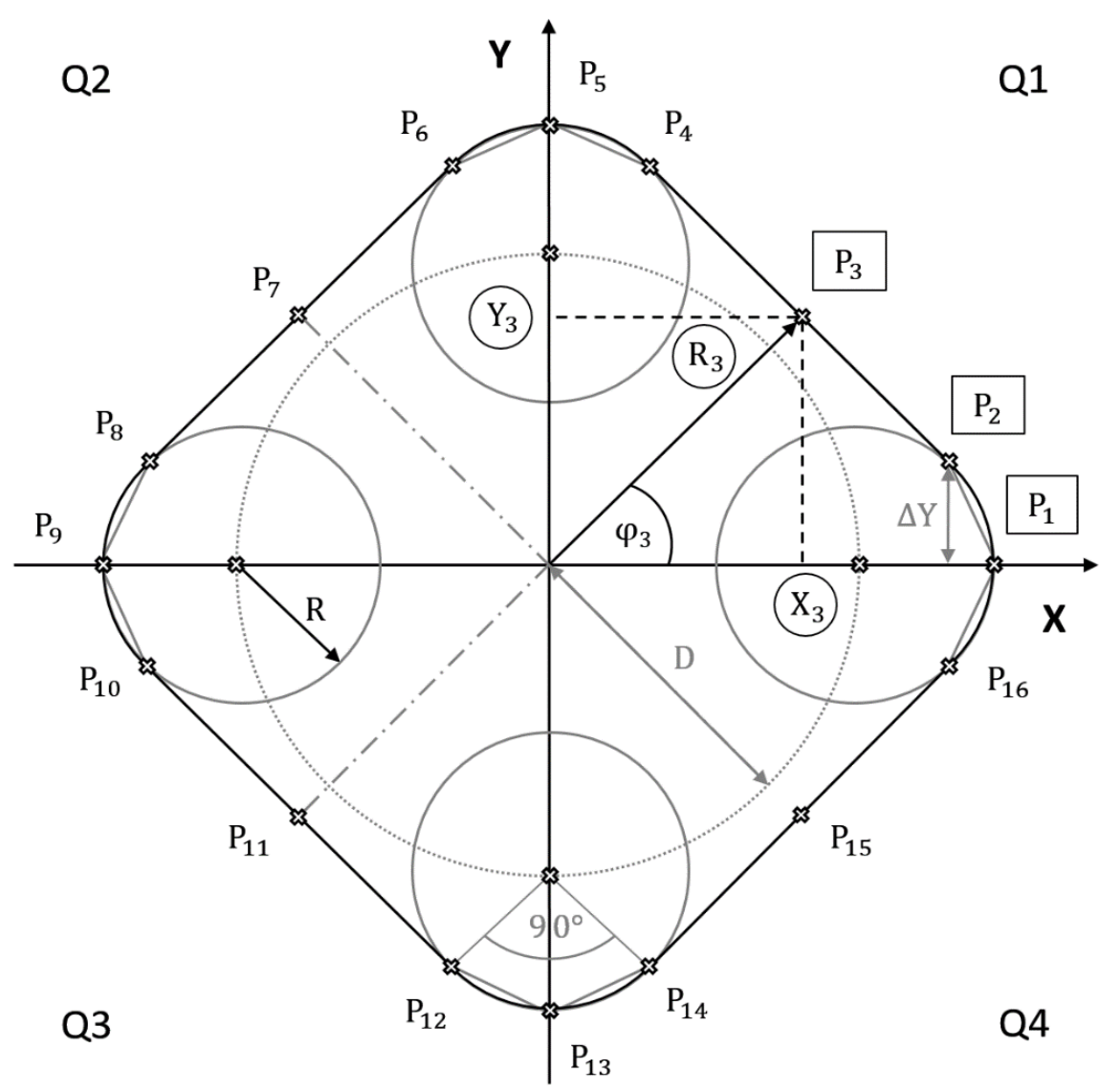

Fig. 2. Illustration of the lateral surface of a pump cam using mirror symmetry.

If the main spindle of the lathe is switched to axis operation, the spindle can be aligned via the C-axis. Equation (9) shows this by using the polar angle $\varphi$, which must be determined for each of the 16 coordinate points on the cam's lateral surface.

$$
\mathrm{C}=\varphi
$$

The polar angle $\varphi_{\mathrm{Q} 1}$ in the first quadrant $\mathrm{Q} 1$ of the $\mathrm{XY}$ plane in figure 2 is calculated according to equation (10) from the ratio of the Cartesian $\mathrm{Y}$ coordinate to the radius $\mathrm{R}_{\mathrm{C}}$ of the cam at the respective coordinate point.

$$
\sin \varphi_{\mathrm{Q} 1}=\mathrm{Y}_{\mathrm{Q} 1} / \mathrm{R}_{\mathrm{C}}
$$

By adding the polar angle from the first quadrant by $90^{\circ}$ for each further quadrant Q2-Q4, the mirror symmetry of the component can also be used to calculate all other polar angles of the 16 coordinate points according to equations (11) to $(13)$.

$$
\begin{aligned}
& \varphi_{\mathrm{Q} 2}=\varphi_{\mathrm{Q} 1}+90^{\circ} \\
& \varphi_{\mathrm{Q} 3}=\varphi_{\mathrm{Q} 1}+180^{\circ} \\
& \varphi_{\mathrm{Q} 4}=\varphi_{\mathrm{Q} 1}+270^{\circ}
\end{aligned}
$$

As already mentioned in equation (5), the polar angle $\varphi$ together with the set feed f per spindle rotation can be used to feed the rolling tool along the Z-axis. According to the three-axis turning process, rolling a rotationally asymmetrical cam results in an offset $\Delta \mathrm{Y}$ between the centre of the quarter circles and the tool tip at the points $\mathrm{P}_{2}, \mathrm{P}_{6}, \mathrm{P}_{10}$ and $\mathrm{P}_{14}$. At these points, the maximum clearance angle of the rolling tool is reduced as a result of the correction angle that occurs as shown in equation (3). Therefore, it may be necessary to extend the three-axis kinematics of the turning machine by a compensating movement of the $\mathrm{Y}$-axis in order to prevent damage to the rolling tool when the radius of the cam is too small or the offset between the centre of the quarter circles and the centre of rotation is too large. 


\subsection{Generation of a four-axis turning operation}

The extension of the tool path by a compensating movement of the $\mathrm{Y}$-axis requires the cam radius $\mathrm{R}_{\mathrm{C}}$ to be determined according to equation (8) at points $\mathrm{P}_{1}, \mathrm{P}_{2}$ and $\mathrm{P}_{3}$. With the calculation of the polar angle for all 16 Cartesian coordinate points as shown in equations (10) to (13) the position of the Y-axis can be calculated via equation (14).

Based on the mirror-symmetrical geometry of the workpiece, all 16 Cartesian coordinate points can be determined from the points $\mathrm{P}_{1}, \mathrm{P}_{2}$ and $\mathrm{P}_{3}$ by rotating the main spindle.

$$
\mathrm{Y}=\sin \varphi \cdot \mathrm{R}_{\mathrm{C}}
$$

Figure 2 shows at point $\mathrm{P}_{3}$ the right-angled triangle consisting of the Cartesian coordinates $\mathrm{X}$ and $\mathrm{Y}$ as sides and the cam radius $\mathrm{R}_{3}$ as hypotenuse. Therefore, equation (15) can be used to determine the position of the $\mathrm{X}$-axis from the previously defined values of the cam radius $\mathrm{R}_{\mathrm{C}}$ and the tool path of the $\mathrm{Y}$-axis from equation (14).

$$
X=\sqrt{R_{C}^{2}-Y^{2}}
$$

In this simultaneous four-axis turning operation by controlling the translatory $\mathrm{X}, \mathrm{Y}$ and $\mathrm{Z}$ axes together with the rotatory $\mathrm{C}$ axis, the tool is positioned orthogonally to the surface of the workpiece. Compared to the three-axis kinematics described above, the advantage is an unlimited clearance angle at the turning tool and the rolling force is applied at each of the 16 defined coordinate points perpendicular to the surface, so that this does not cause any transverse forces during the rolling process in the XY plane. If the eccentricity is low enough so that the machine kinematics do not limit the rotation of the spindle, then this four-axis turning process could lead to a higher dimensional accuracy by a more uniform compression of the sintered metal. In this case, the rolling process will improve the surface quality of the functional surfaces of the component.

\section{Conclusion}

By turning and rolling rotationally asymmetrical workpieces in a CNC lathe machine, the OST project is researching a new type of process route for the production of wear-resistant components made of sintered metal. In order to avoid a collision between tool and workpiece describes this work the mathematical relations for the calculation of the tool paths, which allow the compacting of sintered metal by using a hydrostatically mounted diamond-coated ball. Two manufacturing strategies for an eccentric trunnion and a mirror symmetrical cam have been developed, based on threeaxis kinematics and four-axis simultaneous machining on the CNC lathe.

The limiting factors of the turning process, such as the acceleration of the axes, the block cycle time of the CNC control system and the clearance angle of the tool are discussed by using the movement of the translatory $\mathrm{X}$ and $\mathrm{Z}$ axes together with the rotatory $\mathrm{C}$-axis up to a four-axis kinematics, in which an additional control of the translatory $\mathrm{Y}$-axis takes place. The transfer of the listed equations into a spreadsheet program enables the creation of an NC program according to the DIN 66025 standard, so that the spindle rotation is synchronised with the radial infeed of the turning or rolling tool.

The next step consists of producing a prototype according to the developed process route and measuring the residual compressive stresses via Rontgen diffraction, which should be generated by rolling the workpiece. Future research plans also include the further development of the process route to an industrial series production in order to manufacture rotationally asymmetrical components such as cams economically.

\section{Acknowledgements}

This project (HA project no. 663/18-86) is funded in the framework of Hessen Modell Projekte, financed with funds of LOEWE - Landes-Offensive zur Entwicklung Wissenschaftlich-ökonomischer Exzellenz, Förderlinie 3: KMUVerbundvorhaben (State Offensive for the Development of Scientific and Economic Excellence). Further information can be found at www.innovationsfoerderung-hessen.de.

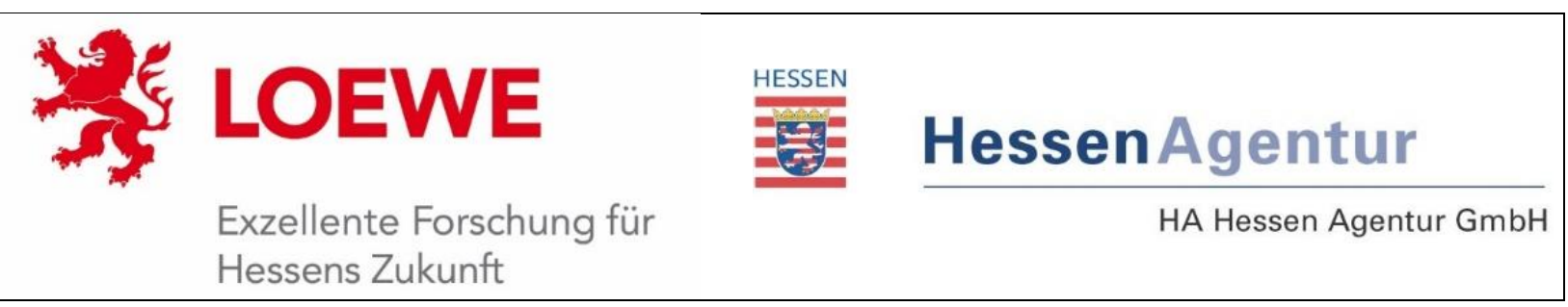

Fig. 3. LOEWE - Project no. 663/18-86 


\section{References}

[1] Röhrle, M. D. (2002). Die Nockenwelle im Wandel der Zeit. MTZ - Motortechnische Zeitschrift, Vol. 63, No. 3, pp. 172-177, DOI 10.1007/BF03226618

[2] Nusskern, P.; Hoffmeister, J. \& Schulze, V. (2014). Powder metallurgical components: Improvement of surface integrity by deep rolling and case hardening, Procedia CIRP, Vol. 13, pp. 192-197, DOI 10.1016/j.procir.2014.04.033

[3] Denkena, B.; Grove, T. \& Maiß, O. (2015). Hartdrehen plus Festwalzen ergibt langlebige Wälzlager. WB Werkstatt + Betrieb, 2015, No. 12, pp. 68-71

[4] Denkena, B.; Grove, T.; Krödel, A. \& Kuhlemann, P. (2016). Kombiniert zum Leistungsplus. WB Werkstatt + Betrieb, 2016, No. 11, pp. 64-67

[5] Habschied, M.; de Graaff, D.; Klumpp, A. \& Schulze, V. (2015). Fertigung und Eigenspannungen, HTM - journal of heat treatment and materials, Vol. 70, No. 3, pp.111-12, ISSN 1867-2493, DOI 10.3139/105.110261

[6] Dubovska, R.; Majerik, J.; Chochlikova, H. \& Baska, I. (2011). Residual Stress Measurement by X-Ray Diffraction Method. Annals of DAAAM for 2011 \& Proceedings of the 22nd International DAAAM Symposium, Vol. 22, No. 1, pp. 1327-1328, ISSN 1726-9679

[7] Dietrich, Jochen (2016). Praxis der Zerspantechnik: Verfahren, Werkzeuge, Berechnung, Springer Vieweg, ISBN 978-3-658-14052-6, Wiesbaden

[8] Weck, M. \& Brecher, C. (2006). Werkzeugmaschinen 4: Automatisierung von Maschinen und Anlagen, Springer Vieweg, ISBN 978-3-540-45366-6, Berlin

[9] Kief, H. B.; Roschiwal, H. A. \& Schwarz, K. (2017). CNC-Handbuch, Carl Hanser, ISBN 978-3-446-45265-7, München 